\title{
Pitfalls in managing depression in older persons - electroconvulsive therapy retains a vital role?
}

\author{
Kevin Kitt ${ }^{1}$, Sabina Fahy ${ }^{2}$, Anne Doherty ${ }^{2}$, Shaun O'Keeffe ${ }^{1}$, \\ Aoife Murray ${ }^{1}$, Eamon Mulkerrin ${ }^{1}$ \\ ${ }^{1}$ Department of Geriatric Medicine, Galway University Hospital, Galway, Ireland; ${ }^{2}$ Department of \\ Psychiatry, Galway University Hospital, Galway, Ireland
}

Received: October 22, 2019

Accepted: December 19, 2019

\section{Correspondence \\ Kevin Kitt \\ Department of Geriatric Medicine, Galway, University Hospital, Galway, Ireland \\ E-mail: kevinkitt2@gmail.com}

\section{Conflict of interest}

The Author declares no conflict of interest

How to cite this article: Kitt $K$, Fahy $S$, Doherty $A$, et al. Pitfalls in managing depression in older persons - electroconvulsive therapy retains a vital role? Journal of Gerontology and Geriatrics 2020;68:188-9. https://doi.org/10.36150/2499-6564-400

C Copyright by Società Italiana di Gerontologia e Geriatria (SIGG)

\section{(c) (1) $(9)$}

\section{OPEN ACCESS}

This is an open access article distributed in accordance with the CC-BY-NC-ND (Creative Commons Attribution-NonCommercial-NoDerivatives 4.0 International) license. The article can be used by giving appropriate credit and mentioning the license, but only for non-commercial purposes and only in the original version. For further information: https://creativecommons.org/licenses/by-nc-nd/4.0/deed.en
A 73 year old bachelor had multiple presentations to secondary and tertiary care facilities. His symptoms were varied, including headache, falls, marked weight loss and dysarthria. He was investigated as a possible stroke but with subsequent major functional decline.

Following extensive investigations and after four months in residential care, major depressive disorder (MDD) was diagnosed. A physical diagnostic label, side effects of, and poor response to, medications complicated the clinical course. Ultimately he was successfully treated with electroconvulsive therapy (ECT). Despite response to ECT, the protracted course contributed to the institutionalisation of the patient. This case highlights the importance of early, accurate diagnosis and effective treatment of depression in older patients.

Key words: geriatrics, depression, somatic, electroconvulsive therapy

\section{CASE REPORT}

A 73 year old man presented to the Emergency Department (ED) in July 2018 with a history of recurrent falls. He was a bachelor, who lived alone, with a sister and brother living close by in the community. He was a reclusive individual, not a frequent attender to his general practicioner and he was independent in all activities of daily living. In the preceding month he had twice attended and been discharged from EDs in affiliated hospitals with symptoms of headache, dizziness and chest pain. Investigations were normal. On admission on this occasion, he had mild ataxia. Magnetic Resonance Imaging (MRI) of the brain showed no recent ischaemia. He was discharged home after two weeks following full stroke work-up, with a diagnosis of possible posterior circulation stroke, which was based on clinical exam.

He was readmitted five days later, reporting bilateral lower limb weakness. There were no neurological findings and repeat neuroimaging was normal. He was discharged to a nursing home for two weeks convalescence where he remained until a review regarding suitability for long-term nursing care in the geriatric outpatient clinic in October 2018. His Montreal Cognitive Assessment (MoCA) was 20/30. There was evidence of tremor and diaphoresis, and he reported paranoid delusions. A major depressive disorder (MDD) was suspected and he was started on sertraline $25 \mathrm{mg}$ and referred to the Psychiatry of Later Life team. Aripiprazole and subsequently haloperidol were introduced for resistant psychotic symptoms. 
He was readmitted in January 2019 with drowsiness, reduced mobility, weight loss and dysarthria. He was bedbound with decubitus ulcers on his heel and buttocks. There were parkinsonian features with no focal neurological deficit or contractures. Detailed collateral history confirmed a depression-related admission to an acute mental health unit when 27 years old. He recovered well from this episode, and did not require long term anti-depressant therapy. He had no further contact with local mental health services until this presentation, forty-six years later.

He was diagnosed with persistent MDD, drug-induced Parkinsonism and possible dementia. The diagnosis of depression was based on clinical history with collateral from family members, with evidence of low mood, diminished interest in activities, weight loss, slowness of thought and diminished ability to concentrate. MRI imaging of brain and spine, CT scans of thorax, abdomen and pelvis, haematological and biochemical tests did not show any other abnormality that would explain his physical decline. He was unable to tolerate rivastigmine due to side effects. Parkinsonian features slowly abated on withdrawal of neuroleptic medications.

His medications were changed to mirtazapine $30 \mathrm{mg}$ daily, and agomelatine was added and titrated to $50 \mathrm{mg}$ daily. Despite partial stabilisation, he remained withdrawn and depressed, with reduced appetite and mobility, and anhedonia. He was unable to cooperate with cognitive testing. Between August 2018, and January 2019, he lost $14 \mathrm{~kg}$ body weight with a further $5 \mathrm{~kg}$ loss at the end of March.

He consented to electroconvulsive therapy (ECT) and received 6 sessions of brief pulse, right unilateral ECT over a 3 week period. The response was dramatic. His mood, cognition, appetite and physical function improved. He regained $5 \mathrm{~kg}$ over four weeks. From being bedbound, he could mobilise with a frame. His MMSE was 29/30 and MoCA was 23/30. Functionally, he was independent at this point, but required long term nursing home care due to lack of confidence and institutionalisation.

\section{DISCUSSION}

Late onset depression remains underdiagnosed and there is evidence that it is undertreated compared to depression in younger sufferers ${ }^{1}$. Older patients report somatic rather than mood symptoms, and the false negative GDS noted in this case probably relates to the predominance of somatic symptoms. A physical diagnosis, such as possible stroke in this case, can be associated with a delayed diagnosis of MDD ${ }^{2}$. Side effects of, and poor response to, medications also complicate the clinical course. While antidepressants remain an effective treatment, first line in the management of depression ${ }^{3}$, there is some evidence that they may be less effective than in younger adults ${ }^{4}$. ECT retains an important role in management of major depression in older adults, especially when speed of response is important where earlier introduction may be appropriate ${ }^{5}$. This case report highlights the difficulties and importance of making an early positive diagnosis of affective disorder and the complexity conferred by comorbidity. We submit this case to highlight to general physicians the potential benefits of ECT, and this is particularly important for geriatricians given that older age has been shown to be a positive predictor of response and remission in major depression ${ }^{6}$.

\section{References}

1 Klap R, Unroe KT, Unutzer J. Caring for mental illness in the United States: a focus on older adults. Am J Geriatr Psychiatry 2003;11:517-24.

2 Huerta-Ramírez R, Bertsch J, Cabello M, et al. Diagnosis delay in first episodes of major depression: a study of primary care patients in Spain. J Affect Disord 2013;150:124751. https://doi.org/10.1016/j.jad.2013.06.009

3 Tham A, Jonsson U, Andersson G, et al. Efficacy and tolerability of antidepressants in people aged 65 years or older with major depressive disorder - a systematic review and a meta-analysis. J Affect Disord 2016;205:1-12. https://doi. org/10.1016/j.jad.2016.06.013

4 Tedeschini E, Levkovitz $\mathrm{Y}$, lovieno N, et al. Efficacy of antidepressants for late-life depression: a meta-analysis and meta-regression of placebo-controlled randomized trials. J Clin Psychiatry 2011;72:1660-8. https://doi.org/10.4088/ JCP.10r06531

5 Spaans HP, Sienaert P, Bouckaert F, et al. Speed of remission in elderly patients with depression: electroconvulsive therapy v. medication. $\mathrm{Br} J$ Psychiatry 2015;206:67-71. 10.1192/bjp.bp.114.148213

6 Van Diermen L, van den Ameele S, Kamperman AM, et al. Prediction of electroconvulsive therapy response and remission in major depression: meta-analysis. Br J Psychiatry 2018;212:71-80. https://doi.org/10.1192/bjp.2018.67 